RUNNING HEAD: TOWARD A CULTURAL ADVANCEMENT

Toward a Cultural Advancement of Tinto’s Theory

Douglas A. Guiffrida

University of Rochester

Warner Graduate School of Education and Human Development

Paper Accepted for Publication in The Review of Higher Education

The author thanks Darrell Leavitt, Derek Seward, and Chris Penders for their assistance in preparing this article. 


\begin{abstract}
Despite the broad appeal of Tinto's (1993) theory, it is not well supported by empirical research, especially when applied to Minority students. While prior critiques of the theory indicate the need to modify Tinto’s notion of breaking away when applying the theory to diverse students, research suggests additional refinements of the theory are also needed. In addition to recognizing the need for students to maintain cultural and familial connections to succeed at college, the author contends that the theory can be advanced by integrating research from social and cross-cultural psychology that has investigated relationships between cultural norms, motivational orientation, and academic achievement and persistence.
\end{abstract}




\section{Toward a Cultural Advancement of Tinto’s Theory}

Tinto’s (1993) theory of student departure is the most widely cited theory for explaining the student departure process and has reached "near paradigmic status" in the field of higher education (Braxton, Milem, \& Sullivan, 2000, p. 107). Yet despite its broad appeal, empirical research provides only modest support for the propositions of the theory (see Braxton \& Lee, 2005; Braxton, Sullivan, \& Johnson, 1997). Moreover, critics have argued that failure of the theory to recognize cultural variables makes the theory particularly problematic when applied to Minority students (Guiffrida, 2005; Hurtado, 1997; Kuh \& Love, 2000; Rendon, Jalomo, \& Nora, 2000; Moore \& Upcraft, 1990; Tierney, 1999).

One significant cultural limitation of the theory that is well established in higher education literature relates to Tinto's (1993) assertion that students need to break away from past associations and traditions in order to become integrated into the social and academic realms of the college. Tierney (1992) argued that Van Gennep’s (1960) transitional model, from which Tinto based this notion of breaking way, is not applicable to Minority college students because the model was intended to describe developmental progression within a culture rather than assimilation from one culture to another. Given that minority students' cultural backgrounds often differ from the Eurocentric frameworks upon which the norms and values at predominately white institutions (PWIs) are based, Tierney argued that this mistaken extraction of Van Gennep’s theory was potentially harmful to Minority students because it encouraged separation from cultural traditions and supportive relationships. Moreover, critics have contended that this aspect of Tinto's theory, which is rooted in the Western, assimilation/enculturation paradigm, 
ignores bicultural integration, or the ability of Minority students to be apart of both the majority and minority cultures to succeed at college (Kuh \& Love, 2000; Rendon, Jalomo, \& Nora, 2000).

Given that substantial research has validated the need for Minority college students to retain and nurture connections to their cultural heritage (see Gonzalez, 2000; Guiffrida, 2003; 2005; Murguia, Padilla, \& Pavel, 1991; Padilla, Trevino, Gonzalez, \& Trevino, 1997) and to draw support from members of their home communities (see Cabrera, Nora, Terenzini, Pascarella, \& Hagedorn, 1999; Delgado, 2002; Eimers \& Pike, 1996; Gloria, Robinson Kurpius, Hamilton, \& Wilson, 1999; Gonzalez, 2000; Guiffrida, 2004; 2005; Hendricks, Smith, Caplow, \& Donaldson, 1996; Hurtado, Carter, \& Spuler, 1996; Nora, 2001; Nora \& Cabrera, 1996; Rosas \& Hambrick, 2002), it is logical to conclude that a cultural advancement of Tinto’s (1993) theory begins by recognizing cultural and familial connections more prominently. However, Rendon, Jaloma, and Nora (2000) asserted that the theory needs to be taken to "an even higher level of theoretical development” (p. 149) in order to be more thoroughly descriptive of Minority students. Similarly, Braxton, Sullivan, and Johnson (1997) concluded that continued elaboration of Tinto’s (1993) theory and integration of additional psychological and cross-cultural perspectives was needed to enhance the theory, especially for applying it to Minority students. Literature from the fields of social and cross-cultural psychology provides potential for an additional multicultural critique and refinement of Tinto's (1993) theory. Specifically, research and theory that have examined relationships between cultural norms, motivational orientation, and college academic achievement and persistence provides potential for advancing Tinto's conceptualization of student commitment; a construct that stands at the core of the theory. Tinto asserted that students enter an institution with certain background characteristics (i.e., family background, skills \& abilities, \& prior schooling) that have shaped their levels of 
commitment for completing their degrees. He also believed that students' levels of commitment were continually shaped by their interactions within the various academic and social systems of the college. According to Tinto, the more students become academically and/or socially integrated into the university, the greater their commitment to completing their degrees. Stage (1989) has noted, however, that while commitment is central to Tinto’s theory, the theory fails to provide an understanding of students' motivational orientations to such commitments. This limitation, while important to consider for all students, may be particularly significant when using the theory to describe Minority student academic achievement and persistence. Research suggests minority students' motivational orientations for attending and succeeding in college may differ from the motivational orientations of their White peers (Allen, 1999; Arnold, 1993; Hurtado, 1994; Pintrich \& Zusho, 2002; Stage, 1989).

Since the most recent iteration of Tinto's (1993) theory, social and cross-cultural psychological researchers have learned a great deal about relationships between cultural norms, motivational orientation, and academic achievement and persistence; however, these advances have yet to be incorporated into Tinto's theory. This paper is an attempt to strengthen Tinto's theory to be more culturally sensitive and, therefore, descriptive of Minority student academic achievement and persistence by integrating these social and cross-cultural psychological principles. The paper begins with a critical review of two salient theories of human motivation: Self-determination theory (Deci \& Ryan, 1991) and Job Involvement Theory (Kanungo, 1982). Key components of each theory are then integrated to create a framework for explaining how cultural norms and motivational orientation impact college student academic achievement and persistence. The viability of the proposed changes is supported by research that has examined 
relationships among motivational orientation, cultural orientation, and academic achievement and persistence.

\section{Self-determination Theory (SDT).}

Self-determination theory (SDT) is one of the most referenced, researched, and validated theories for understanding how socio-cultural conditions interact with people’s inherent psychological needs to shape their behaviors (Reeve, 2002). According to SDT (Deci \& Ryan, 1991), people are motivated to behave, or, in the case of educational motivation, to learn, by one of two motivational orientations: (a) intrinsic motivation, or learning because one finds the content interesting; or (b) extrinsic motivation, which is learning as a means to an end (i.e., grades, praise, pay). SDT posits that the absence of intrinsic or extrinsic motivation results in lack of motivation to learn, which Deci and Ryan refer to as amotivation. SDT is primarily based on the premise that fulfillment of intrinsic needs is more important to personal growth and learning than fulfillment of extrinsic needs. Therefore, the theory posits that the most meaningful and successful learning occurs when students are motivated intrinsically (Reeve, Deci, \& Ryan, 2004).

According to SDT (Deci \& Ryan, 1991), there are three primary components to intrinsic motivation for learning. The first component is the need for autonomy, which occurs when students chose, on their own, to become engaged in learning because the subject and activities are closely aligned to students' interests and values (Reeve, et al., 2004). The second requisite to intrinsic motivation is competence, or "the need to be effective in interactions with the environment” (Reeve, et al., 2004, p. 34). In addition to asserting one’s effectiveness, competence also recognizes the learner's need to test, challenge, and develop in new ways. The 
third requisite to intrinsic needs is relatedness, or the need to establish close, secure relationships with others.

SDT also delineates three forms of extrinsic motivation (Reeve et al., 2004). The least effective form of extrinsic motivation is external regulation, which occurs when students are motivated purely by rewards and punishments from outside sources. A second form of extrinsic motivation, introjected regulation, occurs when students who are motivated by rewards and punishments begin to partially internalize this external pressure to learn. The third type of extrinsic motivation, identified regulation, occurs when the externalized pressure to learn becomes internalized by the student. While research has indicated that both external and

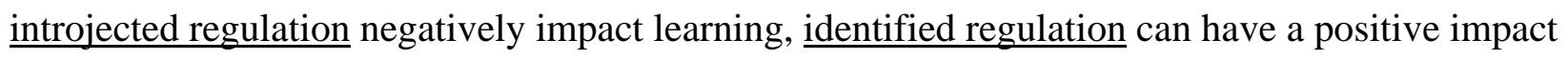
on learning, especially when the material is considered important but uninteresting to the learner (Reeve et al., 2004).

Another important component to SDT is the recognition of how external events support or hinder intrinsic motivation. Reeve et al. (2004) cited extensive research concluding that controlling behaviors on the part of teachers or parents, such as surveillance, threats of punishment, imposed goals, competition, and evaluation, all serve to undermine student intrinsic motivation toward learning. This line of research has also found that parents and teachers who provide students with choices, opportunities for self-direction, rationales, acknowledgement of feelings, and positive feedback increase students’ intrinsic motivation towards learning.

Cross-cultural considerations of SDT. While SDT has been validated in numerous employment and educational settings (see Deci and Ryan, 2002), the theory, like other theories of motivation, has also received criticism regarding its applicability to diverse groups. Crosscultural psychologists have argued that many social psychology theories, including theories of 
motivation, are culturally-bound at not found universally (Berman, 1989; Gaines, et al. 97;

Triandis et al., 98); therefore, it is important to review cross-cultural psychological literature to identify dimensions of cultural variation and to understand how such variations are reflected in college student motivation.

One of the most important behavioral distinctions observed among various cultures of the world is the differences between collectivism and individualism (Triandis, 1998; 1999). Individualist societies tend to value independence, competition, emotional detachment from one's in-group (i.e., family, tribe, etc.), and place personal goals over the goals of the in-group (Phinney, 1996). Collectivist societies value interdependence; group harmony; emotional attachment within the in-group, especially between parent-child; and the subordination of individual goals to the goals of the collective (Triandis et al. 1998). Psychologists and anthropologists have long observed that Western cultures, especially those of the United States, Great Britain, and British influenced countries such as Australia and Canada, tend to be individualist while many non-Western cultures, including those of Africa, Latin America, and Asia, demonstrate cultural orientations that are more collectivist (Beattie, 1980; Fisk, Kitayama; Inkeles, 1983; Marcus, \& Kitayama, 1991; Mead, 1967; Triandis, McCuster \& Hui, 1990). Several cross-cultural psychologists (see Marin \& Marin, 1991; Phinney, 1996) have maintained that collectivist values continue to influence African American, Latino American, Native American, and Asian American cultures, not only as continuation of indigenous values, but also as a means to assist members of these groups in dealing with racial oppression and socioeconomic challenges (Staples \& Mirande, 1980).

While research supports the tendency for Minority Americans to espouse collectivist values (Asante, 1994; Gaines, 1994; O’brien \& Fugita, 1991; Oyserman, Gant, \& Ayer, 1995; 
Sung, 1985; White \& Parham, 1990; Valenzuela \& Dornbush, 1984; Xi, 1994), other studies have been less conclusive in ascribing correlations among ethnicity and collectivism/individualism (e.g., Cross, 1995; Freeberg \& Stein, 1996; Gaines, et al. 1997; Gudykunst et al., 1996; Oyserman, Coon \& Kemmelmeier, 2002; Singelis \& Sharkey, 1995). This lack of consensus in the research has led several cross-cultural psychologists to conclude that while Minority Americans may be more predisposed to collectivist values than White Americans, the terms should not be used categorically (Phinney, 1996; Marcus \& Kitayama, 1991). In fact, researchers have recognized that heterogeneity exists among Minority Americans, due in part to varying degrees of blending with mainstream U.S. culture. These findings have caused leading cross-cultural psychologists to conclude that individualism and collectivism, while salient to understanding antecedents of motivation and human behavior, are not necessarily dichotomous constructs, but rather orthogonal elements that necessarily coexist, to varying degrees, in all humans (Gaines, et al. 1997; Triandis, 1989).

Cross-cultural psychology provides a foundation for a critical examination of how SDT (Deci \&Ryan, 1991) can be used to advance Tinto’s (1993) seminal theory. While SDT provides great potential for advancing the theory to recognize student motivational orientation, the literature that addresses differences between individualism and collectivism points to a potential cross-cultural limitation regarding SDT's conceptualization of autonomy, a key component to intrinsic motivation. SDT asserts that the basic psychological conditions (i.e., autonomy, competence, relatedness) are "a natural aspect of human beings that apply to all people, regardless of gender, group, or culture” (SDT Website, p. 1). However, cross-cultural studies have led some researchers to question whether autonomy is a necessary requisite to well-being in collectivist societies (Bond, 1988; Carver \& Scheier, 2002; Iyenger \& Lepper, 1999; Miller, 
1997; Oishi, 2000). This limitation, which is crucial to recognize when attempting a multicultural advancement of Tinto's (1993) theory, may be particularly vital for applying the theory to students who maintain collectivist orientations.

Cross-cultural research clearly demonstrates the need to consider individualist and collectivist cultural norms when assessing motivational orientation. Furthermore, while the research cautions us to consider the effects of cultural blending and to not broadly categorize all Minority students as collectivist and all White students as individualist, the studies suggest that because of prior socialization, Minority students may be more likely than White students to maintain collectivist values. While SDT provides an important foundation for enhancing our understanding of student commitment, to truly advance Tinto’s (1993) theory in culturally sensitive manner, it is useful to examine a second motivational model that recognizes the impact of varying cultural norms on motivational orientation.

\section{Job Involvement Theory (JIT)}

Although not focused on motivation towards academics and learning, Kanungo’s (1982) motivational approach to involvement and alienation in the workforce offers a complimentary motivational framework that recognizes differences in the motivational orientations of people from collectivist and individualist societies. Like SDT (Deci \& Ryan, 1991), Job Involvement Theory (JIT) asserts that intrinsic and extrinsic forces motivate all human behavior. However, Kanungo challenged the assumption held by many organizational theorists that job involvement, or one's psychological identification with a job, hinged upon the ability of the job to fulfill workers' intrinsic needs. Citing his own pan-cultural research investigating job involvement, Kanungo argued that job involvement depended upon the ability of the job to fulfill the worker's most salient needs, whether intrinsic or extrinsic. 
Kanungo (1982) theorized that workers’ salient needs were shaped by past socialization experiences, including the degree to which workers internalized their societal/cultural norms, and that these needs were continually modified by present job conditions. The result was that different workers, depending upon how they were socialized, developed different need-saliency patterns. For example, Kunungo pointed out that workers who value Western individualist norms often believe that work is central to satisfying salient intrinsic needs for autonomy and competence and salient extrinsic needs for pay, promotion, and personal recognition. Employees socialized in collectivist cultures are more likely to view work as a means for satisfying salient intrinsic needs for relatedness, societal improvement, equity, and harmony, even at the expense of other intrinsic needs such as autonomy or extrinsic rewards such as personal recognition or financial gains.

Kanungo (1981) conducted a study of business managers that illustrated the significance of recognizing workers' salient needs. Contrary to the dominant view of motivation at the time, he found that managers motivated by extrinsic needs, such as pay and promotion, tended to be more involved with their jobs. Employees whose salient needs were more intrinsic were less involved in their jobs. He attributed this to the rewards structure inherent in much of the corporate world, which is based on satisfaction of extrinsic needs through pay, prestige, and promotion.

Although JIT (Kanungo, 1982) has yet to be applied directly to learning or educational persistence, Kanungo has suggested that the model could be used to understand involvement in systems outside the work environment, including involvement patterns within families and communities. Therefore, JIT may be useful for discerning the impact of cultural norms on the need saliency patterns of underrepresented Minority college students. 


\section{Toward a Cultural Advancement of Tinto's (1993) Theory}

Higher education and cross-cultural psychological literature clearly indicate that a cultural advancement of Tinto’s (1993) theory begins by recognizing the need for Minority college students to remain connected to supportive members of their home communities. While Tinto's theory recognizes the impact of family to pre-college commitment, to truly be descriptive of students who espouse collectivist cultural orientations, the theory must also recognize the potential for families and friends from home, or what I refer to broadly as home social systems, to support students once they arrive at college. This assertion is based on several conceptual critiques of Tinto’s theory (see Kuh \& Love, 2000; Hurtado, 1997; Rendon, Jaloma, \& Nora, 2000; Nora, 2001; Tierney, 1992, 1999) and findings from numerous studies that have concluded that minority students can gain tremendous support from families, friends, and other members of their home communities (Cabrera, Nora, Terenzini, Pascarella, \& Hagedorn, 1999; Delgado Bernal, 2002; Eimers \& Pike, 1996; Gloria, Robinson Kurpius, Hamilton, \& Wilson, 1999; Gonzalez, 2000; Guiffrida, 2004, 2005; Hendricks, Smith, Caplow, \& Donaldson, 1996; Hurtado, Carter, \& Spuler, 1996; Nora \& Cabrera, 1996; Rosas \& Hambrick, 2002). In addition recognizing the important role that home social systems have in supporting Minority students at college, a second way in which Tinto’s (1993) theory can be advanced to be more culturally sensitive is by replacing the term integration with the term connection. According to Kuh and Love (2000), integration implies that students must become socialized into the dominant culture of the institution while abandoning their former cultures, but connection recognizes students' subjective sense of relatedness without implying the need to break ties with one's former community. This subtle, yet important change allows the theory to 
recognize that students can become comfortable in the college environment without abandoning supportive relationships at home or rejecting the values and norms of their home communities.

Research also indicates that Tinto’s (1993) theory can be advanced by recognizing more prominently the need for students to maintain connections to their cultural heritages and traditions in order to succeed at college. Although Tinto recognized the need for Minority students to connect with students with shared cultures (i.e., language, dress, religion, values, etc.), Tinto asserted that these cultural connections were largely to facilitate social integration into the college. Tinto also asserted that cultural connections occurred largely within small ethnic enclaves consisting of other Minority college students.

While the need for Minority students to connect with students with shared cultural heritages to succeed at college has been strongly supported by research (DeSousa \& Kuh, 1996; Guiffrida, 2003, 2004; McClung, 1988; Muguia, Padilla \& Pavel, 1991; Padilla, Trevino, Gonzalez, \& Trevino, 1997; Sedlacek, 1987; Sutton \& Kimbrough, 2001; Taylor \& HowardHamilton, 1995), Tinto’s (1993) interpretation excludes the well-documented benefits of connecting with people with shared cultural heritages who are outside the university system. Results of qualitative studies investigating the experiences of Latino (Rosas \& Hamrick, 2002), Chicano (Gonzalez, 2002), Chicana (Delgado Bernal, 2002), Navajo (Jackson \& Smith, 2001), and African American (Guiffrida, 2005) college students have found that students perceived their families and members of their home communities as providing essential cultural connections and nourishment that assisted them in dealing with racism, cultural isolation, and other adversity they experienced at college. These findings suggest that cultural connections play a much larger role in Minority college student persistence than simply facilitating social integration into the university. 
Adding a distinct category highlighting the importance of maintaining cultural connections while at college is another important step in moving the theory away from an integrationist perspective, emphasizing student adaptation to the majority culture, to one that values diversity and encourages colleges and universities to affirm and honor diverse student cultures. Moreover, recognizing that cultural connections can be fulfilled by both university social systems and home social systems allows the theory to better reflect the experiences of a more diverse group of college students, especially those who espouse collectivist orientations.

While the changes outlined above provide an important first step toward advancing the theory to be more descriptive of students who espouse collectivist orientations, research and theory from social and cross-cultural psychology suggest that recognizing student motivational orientation and intrinsic/extrinsic cultural norms provides potential for further refinement of Tinto’s (1993) theory so that it more fully recognizes cultural differences among students. Using SDT (Deci \& Ryan, 1991) as the foundation, successful students are likely to have motivational orientations that are intrinsic, meaning these students (a) are autonomous learners who seek knowledge for its own sake, (b) have demonstrated competence and seek to challenge themselves in order to grow, and (c) feel socially related or connected with significant others. According to the same principles of motivation, students at risk for attrition or low academic achievement at college have either amotivational orientations towards learning or non-self-determined forms of extrinsic motivation

However, given the potential limitations of SDT (Deci \& Ryan, 1991) to be fully descriptive of students from collectivist cultural orientations, it is also useful to incorporate aspects of JIT (Kunugo, 1982) into Tinto’s (1993) theory, which recognizes the effects of cultural norms on individual need saliency patterns. Like SDT, JIT, when translated to explain 
academic achievement and persistence, suggests that successful college students who have internalized individualist cultural norms are likely to succeed if the college environment provides opportunities for them to satisfy their intrinsic needs for autonomy and competence. However, JIT also indicates that successful individualist-oriented students may also be motivated by extrinsic needs for high GPAs in order to obtain successful, well-paying, prestigious jobs upon graduation. This aspect of JIT also suggests that collectivist-oriented students may be at risk for academic under-achievement and attrition if they seek to fulfill salient intrinsic needs for relatedness at the expense of their less salient needs for autonomy, competence, and extrinsic rewards (i.e., GPA, recognition, etc.). Social and cross-cultural psychological theory and research suggest, therefore, that Tinto's theory could be more culturally sensitive by not only recognizing student motivational orientation, but also by recognizing the potential for individualist and collectivist cultural norms to influence motivational orientation.

The motivational and cross-cultural research described in this paper also provides potential for expanding our understanding of the ways in which home social systems support student pre-college and college commitment. Both SDT (Deci \& Ryan, 1991) and JIT (Kanungo, 1982) recognize how students’ social systems, both past and present, influence motivation. According to SDT, successful college students are likely to have interacted with teachers and parents who provided autonomous support to students rather than controlling their academic behaviors. SDT also suggests that continued relationships with social systems that provide autonomy supportive relationships at college, such as peers, faculty, and family members, are necessary to support student intrinsic motivation while at college. Similarly, JIT (Kanungo, 1982) also recognizes the impact of social systems on motivation; however, integrating JIT into Tinto’s (1993) theory allows the theory to recognize how ingrained cultural 
norms impact student need saliency patterns, which, in turn, impact the social systems that students seek to support them at college. For example, a student socialized in an individualist culture may seek to join social systems that fulfill salient intrinsic needs for autonomy and competence and salient extrinsic needs for high GPA and personal recognition. A student socialized in a more collectivist culture might focus on establishing relationships within social systems that fulfill salient intrinsic needs for relatedness and societal harmony instead of systems that support academic achievement.

To summarize, I am asserting that in addition to recognizing the continuing need for cultural and familial connections, Tinto's (1993) theory can be more descriptive of diverse students, especially students who maintain collectivist cultural values, by recognizing relationships between cultural norms, motivational orientation, and academic achievement and persistence. Specifically, the research and theory reviewed in this paper suggest that Tinto's theory will be advanced by recognizing the degree to which (a) student motivational orientation impacts college and pre-college commitment towards academic success and persistence; (b) student motivational orientation is impacted by collectivist or individualist cultural norms; and (c)both home social systems (i.e., teachers, parents, friends, etc.) and at college social systems (i.e., peers, faculty, staff) shape and fulfill students' salient needs (see table 1).

The proposed changes, therefore, allow the theory to not only recognize the impact of motivational orientation on academic goal commitment, but to also acknowledge that cultural norms and home and university social sytems (past and present) can have significant effects upon student motivation and subsequent academic performance and persistence decisions. 


\section{Table 1}

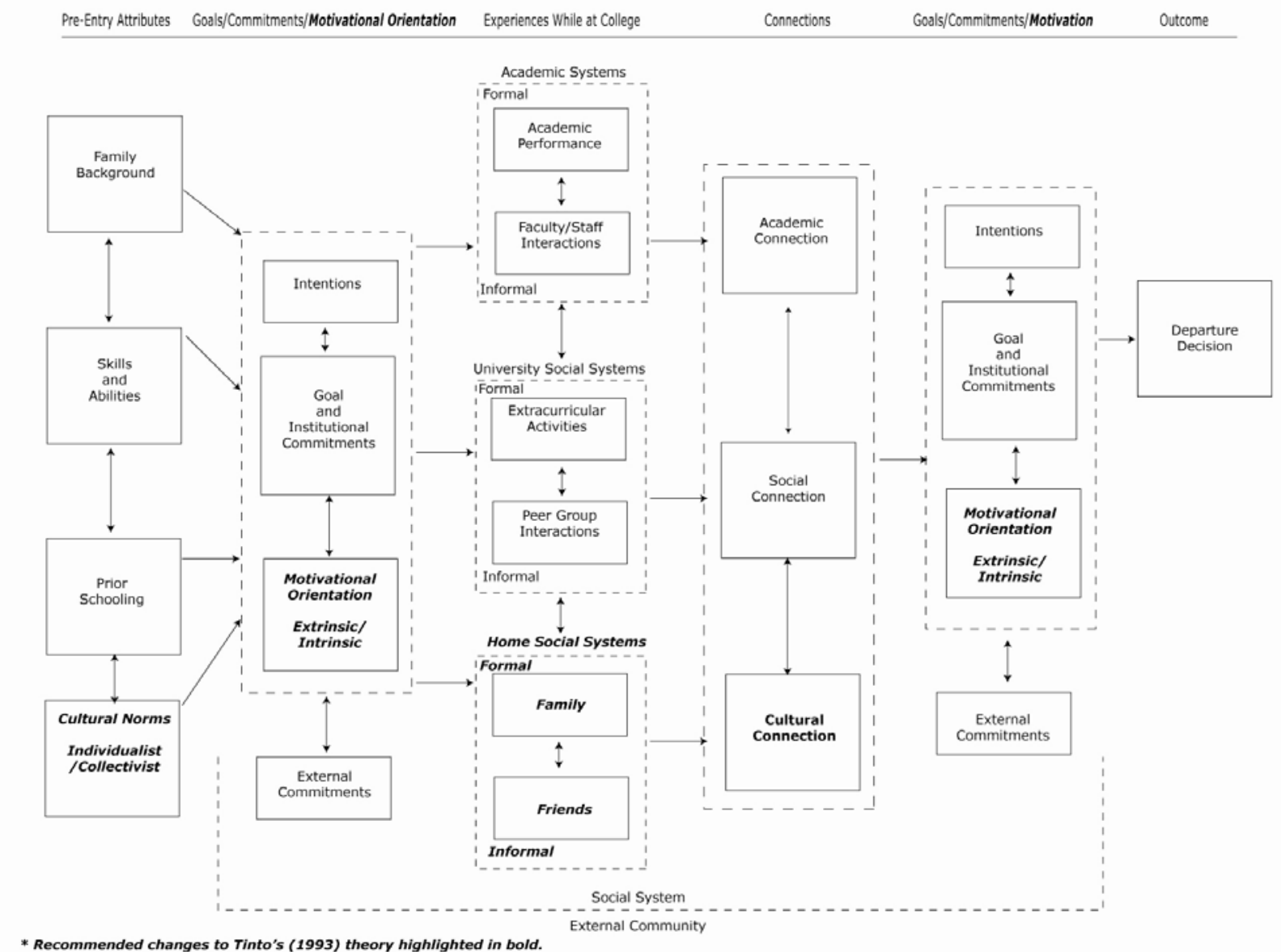

Although the evidence presented thus far to support the need to incorporate motivation and cultural orientation into Tinto’s (1993) theory has been largely conceptual, empirical research examining these constructs has been conducted with college students. I will begin by reviewing research from higher education and social psychological literature that has examined relationships between motivational orientation, social systems, and educational persistence. I will then review studies that have examined relationships between individualism/collectivism, motivation, and Minority college student academic achievement and persistence. Together, these lines of research provide evidence to support further consideration of the proposed changes to Tinto’s theory. 
Motivation, Social Systems, and Academic Persistence

Although neither SDT (Deci \& Ryan, 1991) nor JIT (Kanungo, 1982) have been applied directly to the study of Minority college student academic achievement and persistence, research has examined correlations among motivation and educational persistence in high school and college. In one study, Allen (1999) examined relationships among motivation, student background, academic performance, and persistence with a large group $(n=1000)$ of entering college freshman (mostly Hispanic students) at a medium-sized, public institution located in the Southwest. Allen found a strong relationship between academic motivation and persistence among Minority college students but not among White students. He concluded that motivation provided an important construct for understanding minority student retention. However, Allen only examined students' overall motivational level, which he defined as "desire to finish college" rather than examining student motivational orientation (p. 463). While the results support the proposed advances of Tinto's theory by highlighting differences regarding the impact of motivation between Minority and White students, Allen concluded that more research was needed, especially research that examined student motivational orientation, in order to discover connections between motivation and minority student persistence.

In a second, more comprehensive study that examined college student motivational orientations, Vallerand and Bissonnette (1992) tested the motivational levels of 1,042 first semester students enrolled at a junior college in Quebec to examine if motivational orientation impacted persistence. Consistent with SDT, the researchers concluded that students who persisted in their introductory French course were more intrinsically motivated toward their academics than students with extrinsic or amotivational orientations. However, the researchers did not differentiate between Minority and White participants in describing the sample or in their 
analysis. Therefore, although these results support the positive correlation among intrinsic motivation and academic persistence, the absence of comparisons by student race make it difficult to generalize the results to Minority college students.

In another study that included a comparison of Minority and White student motivational orientations, Stage (1989) surveyed a diverse group of 316 first-year college students attending a Southwestern University to understand how their motivational orientation impacted their levels of academic and social involvement and their persistence. Rather than using the motivational typology described in SDT, Stage developed a system of motivational orientations by conducting a factor analysis using data collected from an educational participation scale. Stage identified three primary classifications of motivational orientations for attending college among the participants that were similar to those inherent in SDT: (a) certification- to earn a degree to get a job; (b) cognitive- to seek knowledge for its own sake; and (c) community service- to prepare to serve mankind. The category labeled certification is clearly related to SDT's extrinsic motivational orientation while Stage's other two main categories, cognitive and community service, can be logically connected to intrinsic motivational orientations. Therefore, the results support the proposed advancements of Tinto’s (1993) theory by highlighting distinct motivational orientations in college students that are consistent with those proposed by SDT.

Stage’s (1989) results also support the proposed framework by recognizing differences in the motivational orientations between successful Minority and White students. Stage concluded that academic integration was more important to the goal commitment of students in the certification (extrinsic) group than social integration and that social integration was most important to the goal commitment of students in the community service (intrinsic) group. However, the reverse was true when examining the data from Minority students: social 
integration was most important to the commitment of Minority students in the certification (extrinsic) group. Stage also found that Minority students in the service (intrinsic) group had less commitment to attain their degrees than White students in the same group. These results support the proposed changes to Tinto’s (1993) theory by noting the positive correlation between intrinsic motivation and academic commitment in White students, while also indicating that successful Minority students may have motivational orientations that are more extrinsic.

Similarly, Cote and Levine (1997) conducted a study to understand relationships between college student motivation and academic achievement. The researchers identified the following five student motivations for attending college: (a) career materialist- to gain money, status, and finer things in life; (b) personal-intellectual development- for personal growth and to understand the complexities of the world; (c) humanitarian- to change systems to help make the world a better place; (d) expectation driven- to satisfy pressures from families and friends; and (e) default- they don’t know why they are attending college. Like Stage’s (1989) study, these categories clearly relate to the motivational orientations delineated in SDT (Deci \& Ryan, 1991) and, as a result, lend themselves to a review of the potential for SDT to help explain college academic achievement and persistence. The personal-intellectual and humanitarian categories are synonymous to SDT’s intrinsic motivation; career materialist and expectation driven are clearly related SDT’s extrinsic motivation; and default is synonymous with SDT's amotivation.

Cote and Levine (1997) surveyed 276 first-year Canadian college students to understand how their motivational orientations related to their acquisition of human capital skills (i.e., selfreport of their learning at college) and GPA. The two motivational categories most closely resembling SDT’s intrinsic motivation (personal-intellectual development \& humanitarian) were found to be the most significant predictors of GPA and human capital skills acquisition. 
Moreover, the two orientations most closely related to extrinsic motivation (career materialist \& expectation driven) were far less likely to predict skills acquisition and GPA and the category resembling SDT's amotivation (default) was significantly negatively correlated with GPA and skills acquisition. The authors concluded that students with personal-intellectual motivational orientations (i.e., intrinsic) represent qualities of "the ideal scholar" that should sought after by universities. Although the sample did not include Minority students, the results supported the proposed advancements of Tinto's (1993) theory by highlighting the importance of intrinsic motivation to the academic success of White students.

Another study that supports the proposed advancement of Tinto’s (1993) theory was conducted by Vallerand, Fortier, and Guay (1997), who tested a large sample of urban high school students ( $\mathrm{n}=4537)$ to examine if the behaviors of teachers, parents, and school administrators influenced students' motivational levels towards learning. Their results support the proposed framework in two ways. First, consistent with SDT (Deci \& Ryan, 1991), they found that the less autonomy supportive that teachers, parents, and school administrators were towards students, the less positive were students’ perceptions of competence and autonomy and, in turn, the lower their levels of intrinsic motivation. The researchers concluded that although personal determinants are important in understanding human motivation to learn, such determinants provide an oversimplified picture for understanding persistence in school. Rather, Vallerand et al. recommended that a more integrated, multidimensional model that included examining interactions among students within various social systems would provide a more complete understanding of motivation and changes in motivation that lead to persistence or attrition in school. Although the study was conducted with mostly White high school students, 
these findings highlight the need to recognize the salient, continuing influence of the home social system to academic persistence.

A second way in which the study by Vallerand et al. (1997) supports the changes proposed in this paper is embedded in a result they found surprising: persistent students displayed higher levels of introjection (a non-self-determined form of extrinsic motivation) than drop out students. The authors hypothesized that this was due to the influence of the students' families. Because students lived at home, they were continually subjected to the influences of their parents to successfully complete their schoolwork. According to this hypothesis, these students would be likely to drop out of school if they attended college while living outside of the home.

Although there has not been a great deal of research that has investigated links between motivation and college student academic achievement and persistence, the limited amount of research in this area supports the need to advance Tinto's (1993) theory in the proposed manner. The literature suggests that social systems impact motivational orientation, which, in turn, affects academic persistence. Moreover, the results from Allen (1999) and Stage (1989) not only recognize the impact of motivational orientation on academic persistence, but also strongly suggest the need to recognize differences in the motivational orientations of Minority students. However, to gain a better understanding of the relationship between motivational orientation and Minority college student academic achievement and persistence, it is also necessary to compare and contrast the proposed changes with the results of research that has examined relationships between college student cultural orientation and motivation. 


\section{Cultural Orientation and Motivation.}

Perhaps the most compelling support form the changes to Tinto’s (1993) theory proposed in this paper come from the results of two studies that have examined how cultural orientation and motivation related to the success of Minority college students. In the first study, Thompson \& Fretz (1991) examined if bicultural adaptive variables predicted levels of social and academic integration among African American students at a PWI. The authors hypothesized that high levels of communalism (i.e., collectivism) would predict successful academic and social integration of African American students at a PWI. They believed that more communal students would be more likely to draw the support of other Blacks on campus and in the surrounding community and less communal students would be at a disadvantage by being less willing and able to find the support needed to thrive at a PWI. The authors surveyed 171, mostly highachieving (mean GPA=2.9) African American students enrolled at large PWI to assess their levels of communalism, attitudes toward cooperation or competitiveness in the classroom, college adjustment, and GPA.

Consistent with the framework proposed in this paper, the results from Thompson and Fretz (1991) highlight the need to understand differences in collectivism and individualism among Minority college students to better understand commitment towards academic achievement and persistence. Contrary to their predictions, Thompson and Fretz found that positive rather than negative attitudes towards competitive learning situations were associated with social adjustment towards college. They also were surprised to find that academically adjusted African American students had more positive attitudes toward individualist and competitive learning environments than African American students who were less academically adjusted. The results support the recommended changes to Tinto’s (1993) theory by indicating 
that minority students with more collectivist orientations may have difficulty becoming integrated into the more competitive, individualist academic and social culture that prevails at many PWIs. Furthermore, the results suggest that academically successful Minority students come in with or adapt individualist values in order to succeed at college. Thompson and Fretz concluded that many successful minority students have learned to integrate into the "culture of competitive learning that characterizes the majority of academic environments” (p. 446).

A second motivational study of college students that incorporated an assessment of cultural norms related to collectivism and individualism was conducted by Dennis, Phinney, and Chuatecto (2005). Recognizing that cultural values influence student motives for attending college, the researchers surveyed 100 first- generation Latino students attending an urban commuter university located on the west coast to understand how personal motivational characteristics related to college adjustment. The authors assessed the extent to which students were motivated to attend college based on career/personal motivation (i.e., personal interest, intellectual curiosity, \& desire to attain fulfilling careers) or family expectation motivation (to meet the expectations of the family). The authors hypothesized that because minority students are heavily influenced by collectivist values, both career/personal and family expectation motivation would be important predictors of college adjustment for these minority students.

Consistent with their hypothesis, Dennis et al., (2005) found that career/personal motivation was a predictor of college adjustment and a slight predictor of college commitment when controlling for other variables such as high school GPA. However, contrary to their expectations, family expectation motivation was not significantly related to college adjustment and commitment when controlling for other variables. The authors concluded that although many minority students are motivated by both individually-oriented and family-based forms of 
motivation, the individual-based motivations were more closely related to college adjustment and commitment. Additionally, the authors concluded that while many of these minority students lived in families and communities that likely valued collectivist norms, it was the ability of minority students to also integrate individualist norms that "may be most predictive of academic success in the United States” (p. 233).

The results from Dennis et al., (2005) provide additional support for the changes to Tinto's theory that are proposed in this paper. The career/personal motivation, which was found to be the most predictive of academic adjustment and commitment, shares obvious characteristics with SDT's intrinsic motivation, most notably in the areas of autonomy (i.e., personal interest, intellectual curiosity) and competence (i.e., satisfaction). The career/personal motivation category also shared important elements of SDT's highest, most internalized form of extrinsic motivation, called identified regulation (i.e., to get into an interesting and satisfying career). The findings support the proposed changes by indicating that successful Minority college students who have internalized individualist cultural norms are most likely to succeed in college environments that provide opportunities for them to satisfy intrinsic needs for autonomy and competence and extrinsic needs to obtain successful careers. The results also support the assertion that more collectivist and/or amotivational orientations (i.e., attending college to fulfill family expectations) were negative predictors of college adjustment and commitment for Minority students. Taken together, the results from Thompson and Fretz (1991) and Dennis et al. provide powerful support for the need to consider college student cultural norms and motivational orientation when attempting to assess academic achievement and persistence decisions. 


\section{Conclusion}

It is difficult to understand completely students' motivations toward their academics or the social systems that may influence these motivations, especially given the largely subjective nature of the data used in constructing the proposed changes to Tinto’s (1993) theory. Additionally, intrinsic/extrinsic motivations are not necessarily mutually exclusive and, therefore, can be difficult to differentiate. For example, some students who seek to attain a high GPA to fulfill salient extrinsic needs for prestige and financial rewards may also be partially motivated by intrinsic interests in learning or to support their families upon graduation. It is also possible that some unsuccessful students may use intrinsically rewarding experiences as diversions from academic work that may be too difficult, a phenomenon Simons, Van Rheenen, and Covington (1999) observed in an academically unsuccessful group of student athletes they labeled “failure avoiders” (p. 160).

Although integrating an assessment of cultural norms and motivational orientation may not provide all the elements needed to fully validate Tinto’s (1993) theory, the proposed changes allow the theory to recognize how diverse socialization experiences impact motivation toward academic achievement and persistence, and, as a result, provide a more comprehensive, multicultural understanding of student commitment. The results of this review suggest that integrating the proposed motivational framework into Tinto’s theory may enhance the theory to be more culturally sensitive and, thus, more descriptive of diverse students, especially students maintaining cultural norms that are more collectivist.

The refinements to Tinto’s (1993) theory described in this paper warrant further testing, not only as a means for advancing Tinto’s theory, but also to assist practitioners in supporting and retaining diverse college students. The propositions asserted in this paper, if proven valid by 
additional research, would allow college faculty and staff who are aware of students' salient motivational orientations to effectively connect students to university social systems that fulfill these salient needs. For example, students who maintain collectivist societal values may benefit from being connected early-on to ethnic/cultural student organizations that emphasize fulfillment of collectivist needs for relatedness and social change. At the same time, however, faculty and staff members could also caution collectivist-oriented students regarding the potential for involvement with collectivist-focused social systems to interfere with student academic achievement. Additionally, the proposed changes to Tinto's theory may enforce the need for college administrators, faculty, and staff to recognize collectivist-oriented initiatives, including activities focusing on social change and relatedness on campus and in society, when assessing academic success.

Future research seeking to test the assertions made in this paper should begin by attempting to identify the cultural norms (i.e., collectivist/individualist) and motivational orientations of a diverse group of students and to examine relationships among these variables and student academic achievement and persistence. This line of research will not only enhance the predictive validity of Tinto’s (1993) theory, but will also allow more subtle, complex differences among students of varying backgrounds to emerge. Additionally, future research should seek to identify other cultural variations beyond individualism and collectivism that may impact motivation towards academic achievement and persistence. Finally, research seeking to enhance Tinto's theory should attempt to understand in more detail how student motivational orientation is impacted by university and home social systems in order to understand the complex influences of these systems on student academic achievement and persistence. 


\section{References}

Allen, D. (1999). Desire to finish college: An empirical link between motivation and persistence. Research in Higher Education, 40 (4), 461-485.

Arnold, K. D. (1993). The fulfillment of promise: Minority valedictorians and salutatorians. The Review of Higher Education, 16(3), 257-283.

Asante, M. K. (1994). The Afrocentric idea. In R. Takaki (Ed.), From different shores:

Perspectives on race and ethnicity in America (2nd ed., pp. 283-287). New York: Oxford University Press.

Beattie, J. (1980). Representations of the self in traditional Africa. Africa, 50, 313-320.

Berman, J.J. (1989). Cross-Cultural Perspectives: The Nebraska Symposium on Motivation, 1989. Lincoln, NB: University of Nebraska Press.

Bond, M. H. (1988). The cross cultural challenge to social psychology. Newberry Park, CA: Sage.

Braxton, J.M., \& Lee, S.D. (2005). Toward reliable knowledge about college student departure. In A. Seidman (Ed.), College student retention: Formula for student success (pp107128). Westport, CT: Praeger Publications.

Braxton, J. M., Milem, J. F., \& Sullivan, A. S. (2000). The influence of active learning on the college student departure process: Toward a revision of Tinto's theory. Journal of Higher Education, 71(5), 569-590.

Braxton, J. M., Sullivan, V. S., \& Johnson, R. M. (1997). Appraising Tinto's Theory of College Student Departure. In J. C. Smart (Ed.), Higher education: Handbook of theory and research, Vol. XII (pp. 107-164). New York: Agathon Press. 
Cabrera, A. F., Nora, A., Terenzini, P. T., Pascarella, E., \& Hagedorn, L. S. (1999). Campus racial climate and the adjustment of students to college. The Journal of Higher Education, 70(2), 134-160.

Carver, C. S., \& Schneier, M.F. (2000). Autonomy and self-regulation. Psychological Inquiry, 11, 284-290.

Clarke, R.M. (1983). Family life and school achievement. Chicago: The University of Chicago Press.

Côté, J. E. \& Levine, C. (1997). Student motivation, learning environments, and human capital acquisition: Toward an integrated paradigm of student development. Journal of College Student Development, 38(3), 229-243.

Cross, S. E. (1995). Self-construals, coping, and stress in cross-cultural adaptation. Journal of Cross-Cultural Psychology, 26, 673-697.

Deci, E. L., \& Ryan, M. R. (1991). A motivational approach to self: Integration in personality. In R. Dienstbier (Ed.), Nebraska symposium on motivation (Vol. 38, pp. 237-288). Lincoln, NB: University of Nebraska Press.

Deci, E. L., \& Ryan, R. M. (2002). Handbook of self-determination research. Rochester, NY: University of Rochester Press.

Delgado, D. B. (2002). Learning and living pedagogies of the home. International Journal of Qualitative Studies in Education, 14(5), 623-639.

Dennis, J. M., Phinney, J. S., \& Chuateco, L. I. (2005). The role of motivation, parental support, and peer support in the academic success of ethnic minority first-generation college students. Journal of college Student Development, 46(3), 223-236.

Durkheim, E. (1951). Suicide. New York: Free Press. 
Eimers, M. T., \& Pike, G. R. (1996). Minority and non-minority adjustment to college: Differences or similarities? (AIR Annual forum Paper No. Eric \# ED397707.).

Fiske, A. P., Kitayama, S., Markus, H. R., \& Nisbett, R. E. (1998). The cultural matrix of social psychology. In D. Gilbert, S. Fiske, \& G. Lindzey (Eds.), Handbook of social psychology (4 ${ }^{\text {th }}$ ed., Vol. 2, pp. 915-981). Boston: McGraw-Hill.

Freeburg, A. L., \& Stein, C. H. (1996). Felt obligation towards parents in Mexican-American and Anglo-American young adults. Journal of Social and Personal Relationships, 13, 457471.

Gaines, S. O., Jr. (1994). Generic, stereotype, and collectivistic models of interpersonal resource exchange among African American couples. Journal of Black Psychology, 20, 291-301.

Gaines, S. O., Jr., Marelich, W. D., Bledsoe, K. L., Steers, W. N., Henderson, M. C., Granrose, C. S., et al. (1997). Links between race/ethnicity and cultural values as mediated by racial/ethnic identity and moderated by gender. Journal of Personality and Social Psychology, 72(6), 1460-1476.

Gloria, A. M., Robinson Kurpius, S. E., Hamilton, K. D., \& Willson, M. S. (1999). African American students' persistence at a predominantly White university: Influences of social support, university comfort, and self-beliefs. Journal of College Student Development, 40(3), 257-268.

Gonzalez, K.P. (2000). Campus culture and the experiences of Chicano students in a predominantly White university. Urban Education, 37, (2) 193-218.

Gudykunst, W. B., Matsumoto, Y., Ting-Toomey, S., Nishida, T., \& Kim, K. S., \& Heyman, S. (1996). The influence of cultural individualism-collectivism, self-construals, and 
individual values on communication styles across cultures. Human Communication Research, 22, 510-543.

Guiffrida, D.A. (2003). African American student organizations as agents of social integration. Journal of College Student Development, 44, (3), 304-320.

Guiffrida, D. A. (2004). Friends from home: Asset and liability to African American students attending a predominantly White institution. NASPA Journal, 24(3) 693-708.

Guiffrida, D. A. (2005). To break away or strengthen ties to home: A complex question for African American students attending a predominantly White institution. Equity and Excellence in Education. 38(1), 49-60.

Hendricks, A. D., Smith, K., Caplow, J. H., \& Donaldson, J. F. (1996). A grounded theory approach to determining the factors related to the persistence of minority students in professional programs. Innovative Higher Education, 21(2), 113-126.

Hurtado, A. (1997). Understanding multiple group identities: Inserting women into cultural transformations. Journal of Social Issues, 53(2), 299-328.

Hurtado, S. (1994). Latino Consciousness and Academic Success. In A. Hurtado, E. E. García \& R. Buriel (Eds.), The educational achievement of Latinos : barriers and successes. Santa Cruz, CA: Regents of the University of California.

Hurtado, S., Carter, P. F., \& Spuler, A. (1996). Latino student transition to college: Assessing difficulties and factors in successful college adjustment. Research in Higher Education, 37(2), 135-158.

Inkeles, A. (1983, November/December). The American character. The Center Magazine, 25-39. Iyengar, S. S., \& Lepper, M. R. (1999). Rethinking the value of choice: A cultural perspective on intrinsic motivation. Journal of Personality \& Social Psychology, 76(3), 349-366. 
Jackson, A.P., \& Smith, S.A. (2001). Postsecondary transitions among Navajo Indians. Journal of American Indian Education, 40 (2). 28-47.

Kanungo, R. N. (1981). Work alienation and involvement: Problems and prospects. International Review of Applied Psychology, 30, 1-15.

Kanungo, R. N. (1982). Work alienation: an integrative approach. New York: Praeger.

Kuh, G.D., \& Love, P.G. (2000). A cultural perspective on student departure. In J. M. Braxton (Ed.), Reworking the student departure puzzle (pp. 196-212). Nashville: Vanderbilt University Press.

Marin, G., \& Marin, B. (1991). Research with Hispanic populations. Newbury Park, CA: Sage. Markus, H. R. \& Kitayama, S. (1991). Culture and the self: Implications for cognition, emotion, and motivation. Psychological Review, 98(2), 224-253.

Mead, M. (1967). Cooperation and competition among primitive people. Boston: Beacon Press. Miller, J. G. (1997). Cultural conceptions of duty: implications for motivation and morality. In D. Munro, J. F. Schumaker, \& A. C. Carr (Eds.), Motivation and Culture (pp. 178-192). New York: Routledge.

Moore, L. V., \& Upcraft, M. L. (1990). Theory in student affairs: Evolving perspectives. In L. V. Moore (Ed.), New directions for student services (Vol. 51, pp. 3-24). San Francisco: Jossey-Bass.

Muguia, E., Padilla, R. V., \& Pavel, M. (1991). Ethnicity and the concept of social integration in Tinto's model of institutional departure. Journal of College Student Development, 32, 433-439. 
Nora, A. (2001). The depiction of significant others in Tinto's "rites of passage": A reconceptualization of the influence of family and community in the persistence process. Journal of College Student Retention, 3 (1) 41-56.

Nora, A., \& Cabrera, A. F. (1996). The role of perceptions of prejudice and discrimination on the adjustment of minority students to college. Journal of Higher Education, 67(2), 119-148.

O'Brian, D. J., \& Fugita, S. S. (1991). The Japanese American experience. Bloomington, IN: Indiana University Press.

Oishi, S. (2000). Goals as cornerstones of subjective well-being: Linking individuals and cultures. In E. Diener \& E. M. Suh (Eds.), Culture and subjective well-being (pp. 87112). Cambridge, MA: Bradford.

Oyserman, D., Coon, H.M., \& Kemmelmeier, M. (2002). Rethinking individualism and collectivism: Evaluation of theoretical assumptions and meta-analyses. Psychological Bulletin, 128 (1), 3-72.

Oyserman, D., Gant, L., \& Ager, L. (1995). A socially conceptualized model of African American identity: Possible selves and school persistence. Journal of Personality and Social Psychology, 69, 1216-1232.

Padilla, R. V., Trevino, J., Gonzalez, K., \& Trevino, J. (1996). Developing local models of minority student success. Journal of College Student Development, 38(2), 125-138.

Pintrich, P.R., \& Zusho, A. (2002). Student motivation and self-regulated learning in the college classroom. In J.C. Smart (Ed.) Higher education: Handbook of theory and research, Vol 17, (pp. 55-128). New York: Agathon Press.

Phinney, J. S. (1996). When we talk about American ethnic groups, what do we mean? American Psychologist, 51, 918-927. 
Reeve, J. (2002). Self-determination theory applied to educational settings. In E. L. Deci \& M. R. Ryan (Eds.), Handbook of self-determination theory and research. Rochester, NY: University of Rochester Press.

Reeve, J., Deci, E.L., \& Ryan, R.M. (2004). Self-determination theory: A dialectical framework for understanding sociocultural influences on student motivation. In D. M. McInerney \& S. Van Etten (Eds.), Big theories revisited (Vol. 4). Greenwich, CN: Information Age Publishing.

Rendon, L. I., Jalomo, R. E., \& Nora, A. (2000). Theoretical considerations in the study of minority student retention in higher education. In J. M. Braxton (Ed.), Reworking the student departure puzzle (pp. 127-156). Nashville: Vanderbilt University Press.

Rosas, M., \& Hamrick, F.A. (2002). Postsecondary enrollment and academic decision making: Family influences on women college students of Mexican descent. Equity and Excellence in Education, 35(1), 59-69.

Self-Determination Theory (2005). Self-determination theory: An approach to human motivation and personality. Retrieved August 18, 2005, from http://www.psych.rochester.edu/ SDT/theory.html

Simons, H. D., Van Rheenen, D. \& Covington, M. V. (1999). Academic motivation and the student athlete. Journal of College Student Development, 40(2), 151-162.

Singelis, T. M., \& Sharkey, W. F. (1995). Culture, self-construal, embarrassability. Journal of Cross-Cultural Psychology, 26(6), 622-644.

Stage, F. K. (1989). Motivation, academic and social integration, and the early dropout. American Educational Research Journal, 26(3), 385-402. 
Stapes, R., \& Mirandé, A. (1980). Racial and cultural variations among American Families: A decennial review of the literature on minority families. Journal of Marriage and the Family, 42, 887-903.

Sung, B. L. (1985). Bicultural conflicts in Chinese immigrant children. Journal of Comparative Family Studies, 16, 255-269.

Thompson, C.E., \& Fretz, B.R. (1991). Predicting the adjustement of Black students at predominantly white institutions, The Journal of Higher Education, 62 (4), 437-450.

Tierney, W. G. (1992). An anthropological analysis of student participation in college. The Journal of Higher Education, 63(6), 603-618.

Tierney, W. G. (1999). Models of minority college-going and retention: Cultural integrity versus cultural suicide. Journal of Negro Education, 68(1), 80-91.

Tinto, V. (1993). Leaving college: Rethinking the causes and cures of student attrition (2nd ed.). Chicago; University of Chicago Press.

Triandis, H.C. (1999). Cross-cultural psychology. Asian Journal of Social Psychology, 2, 127143.

Triandis, H. C. (1989). Cross-cultural studies of individualism and collectivism. In J. Berman (Ed.), Nebraska Symposium on Motivation: Cross Cultural Perspectives (pp. 41-133). Lincoln, NB: University of Nebraska Press.

Triandis, H. C. (1989). The seld and social behavior in differing culutral contexts. Psychological Review, 96, 506-520.

Triandis, H.C., Bontempo, R., Villareal, M.J., Asai, M., \& Lucca, N. (1988). Individualism and collectivism: Cross-cultural perspectives on self-ingroup relationships. Journal of Personality and Social Psychology, 54 (2), p. 323-338. 
Triandis, H.C., Chen, X.P., \& Chan, D.K. (1998). Scenarios for the measurement of collectivism and individualism. Journal of cross-cultural psychology, 29, (2), 275-289.

Triandis, H. C., Chen, X. P., \& Chan, D. K. (1998). Scenarios for the measurement of collectivism and individualism. Journal of Cross-Cultural Psychology, 54(2), 323-338.

Triandis, H. C., McCusker, C., \& Hui, C. H. (1990). Multicultural probes of individualism and collectivism. Journal of Personality and Social Psychology, 59(5), 1006-1020.

Valenzuela, A., \& Dornbusch, S. M. (1994). Familism and social capital in the academic achievement of Mexican orgin and Anglo adolescents. Social Science Quarterly, 75, 1836.

Vallerand, R. J., \& Bissonnette, R. (1992). Intrinsic, extrinsic, and amotivational styles as predictors of behavior: A prospective study. Journal of Personality, 60(3), 599-620.

Vallerand, R. J., Fortier, M. S., \& Guay, F. (1997). Self-determination and persistence in a reallife setting: Toward a motivational model of high school dropout. Journal of Personality and Social Psychology, 72(5), 1161-1176.

Van Gennep, A. (1960). The rites of passage. Translated by M. Vizedon and G. Caffee. Chicago: University of Chicago Press.

White, J. H., \& Parham, T. A. (1990). The psychology of Blacks: An African-American perspective (2nd ed.). Englewood Cliffs, NJ: Prentice Hall.

Xi, C. (1994). Individualism and collectivism in American and Chinese societies. In A. Gonzalez, M. Houston, \& V. Chen (Eds.), Our voices: Essays in culture, ethnicity, and communication (pp. 152-158). Los Angeles: Roxbury.

Yankelovich, D. (1972). Changing values on campus: Political and personal values of today's college students. New York: Washington Square Press. 
Westwood, R.I. (2001, July). Shiney, happy people; or eros rampant: The systemic promotion of the positive and elision of the negative in western motivation theory. Paper presented at the Critical Management Studies Conference, . 
Cultural Advancement 38 